\title{
An empirical approach to wisdom processes
}

\author{
Ioana Laura Dumbravă ${ }^{1}$ \\ ${ }^{1}$ Department of Psychology, School of Psychology and Educational Science, Babeș-Bolyai University, Cluj-Napoca, \\ Romania.
}

Received 16.09.2017; Received revised 15.12.2017; Accepted 20.12.2017

Available online 31.12.2017

\begin{abstract}
In psychology, wisdom gradually received more and more interest form researchers. The first who have directed their attention to this area were the Greek philosophers, but gradually theoretical models were developed based on empirical data and components that explain the development of wisdom. In this paper, we used Ardelt's approach, which takes into account both the eastern and western approaches regarding wisdom. Within a sample of students $(\mathrm{N}=100$, mean age $=24 \mathrm{~m}$, $\mathrm{SD}=6.44$ ), wisdom was investigated in relation to several phenomena that could be involved in the development of wisdom and wisdom processes. Thus, wisdom is studied in relation to general metacognition, moral metacognition, cognitive empathy, emotional empathy, irrationality and cognitive flexibility. The results were found to be in accordance with the hypothesis of affective empathy, identifying a significant positive relationship between the two variables. One must consider that the rest of the correlations were negative and significant, thus drawing attention to other possible factors that might be important in describing wisdom. Variables evaluated were found to explain the variance of wisdom.
\end{abstract}

Keywords: wisdom, metacognition, empathy, cognitive flexibility, irrationality.

Address of correspondence: Ioana Laura Dumbravă, Department of Psychology, School of Psychology and Educational Science, Babeș-Bolyai University, Str. Mihail Kogălniceanu, nr. 1, 400084, Cluj-Napoca, Romania.

E-mail: dumbravaioanalaura.gmail.com

Acknowledgement: This study was funded by The Performance Scholarship awarded by Babeș-Bolyai University, in November 2016.

\section{Introduction}

Wisdom has been a topic of general interest since ancient times. Although initially it was considered that wisdom belongs only to the divinity, gradually the interest was oriented towards human wisdom. Pioneers in this field were philosophers in ancient Greece (Kékes, 1988; Nussbaum, 2001 Taylor, 1955 cit in Baltes and Smith, 2008). Ever since it came to the attention of philosophers, there was a strong argument regarding the components defining wisdom. For example if it only involves extensive use of practical knowledge to cope with various life problems, or requires technical and theoretical knowledge; another issue was the need to be moral in order to be wise (Baltes and Smith, 2008, p. 56-57).

Since ancient times, a wise person was often praised and privileged in the community. This is reported by historians, showing us that, since ancient times in rural or tribal communities, important decisions were taken with the advice of "the wisest of the community". "Decisions by direct vote of the members of the group were influenced by "good and old" group, which had authority because of their age, experience and earned respect" (author anonymous). If you were to ask those people from the past why there was a person designated to be wise, in what way is that person wise, we could get answers that would indicate the importance of age or accumulated experience. We might agree with them and rely on the fact that the elements of wisdom are age and experience. However studies regarding wisdom had shown that age is not directly related to the development of wisdom. Moreover, some authors have shown that the kernel of wisdom is present since adolescence (Baltes and Smith, 2008).

\section{The importance of wisdom}

Why is wisdom important? At the common sense level, each of us can give an answer that is partially true because initial attempts to explain wisdom were based on 
beliefs, theories and the meaning that people gave to wisdom (Bluck, Gluck, 2005, in Benedikovicova \& Ardelt, 2008). But how can we scientifically support the information obtained from the common sense? What would be the elements that define and characterize a person as being wise? What benefits or costs does wisdom bring to humankind? These are a few of the questions that literature still failed to fully respond to, although significant progress has been made in recent decades.

Studies in the field of wisdom have shown that it is associated with better decisions, with better reasoning and actions contributing to a happy life (Kékes 1983, 1988; Maxwell, 2004; Nozick, 1989; Nussbaum, 2001; Thiele 2006 in Baltes and Smith, 2008). Most aspirations and efforts of people turn to trying to be happy, to live a life as happy as it is possible. If wisdom is involved in happiness, then this might be a way to be happy or to be less unhappy. The attention paid to the study of wisdom is in opposition to the effect of positive-negative asymmetry which occurs in psychology. This asymmetry is illustrated in the meta-analysis of Czapinski (1985), in which prevailing efforts of researchers in the field of psychology were to investigate the challenges of psychopathology (69\% of research) rather than to investigate the positive of human nature (31\% research) (in Baumeister, Bratslavsky and Finkenauer, 2001). The involvement of wisdom in rationality would be partially related to the previous reasons, to reduce distress and increase happiness, because rationality puts us in line with reality and thus frees us from desires that are unattainable and make us unhappy (eg. global assessments, rigid thinking) (Daniel David, 2006). Data from studies which investigated wisdom have shown that it is positively correlated with mental health, satisfaction with life and ability to adapt to: social declines, physical declines and even near death experiences (Achenbaum and Orwoll, 1991; Bianchi, 1994; Chinen, 1987; Clayton, 1982; Erikson, 1982; Erikson et al., 1986; cit in Ardelt, 2003, p. 276).

Given the literature and the benefits that wisdom could provide to wise people, wisdom becomes an area of valuable research to investigate possible factors involved in resilience, more specifically the factors that when faced with a negative or traumatic event help some of us to avoid suffering dysfunctional negative emotions (eg depression, anxiety), even more so, facilitate normal or better behaviors than those initially expected (Snyder and Lopez, 2002, chap. 6, p. 76).

Starting from the debates triggered by wisdom's composition, several theories have tried to explain what wisdom is and what its defining components are. In the following paragraphs I will review the most popular theoretical models, focusing on the theory that will be used as framework. The empirical study of wisdom is dated in 1970, when efforts were aimed at defining wisdom, seeking development of measurement tools and applying knowledge acquired about wisdom in various fields of life (Staudinger and Glück, 2011).

\section{Main theoretical approaches}

One of the theories that attempted to describe and provide an explanatory model of wisdom is Sternberg's theory. Thus, from the perspective of this theory wisdom is defined as "the application of intelligence, creativity and knowledge mediated by values, towards achieving the common good through a balance as regards its interests: (a) intrapersonal, (b) interpersonal and (c) extrapersonal on (a) a short period of time and (b) a long period of time, in order to achieve a balance between (a) the adaptation of the existing environment, (b) modification of the environment, and (c) selecting a new environment "(Sternberg, Reznitskaya, Jarvin, 2007, p.145). According to this definition wisdom does not only refer to maximizing their own interests or those of others, on the contrary, wisdom refers to balancing many interests, specifically balancing personal interests (intrapersonal interests), interests held by others (interests interpersonal), and the more general issues related to the community's social and religious interests (extra personal interests). We can not talk about wisdom when individual motivation is to maximize the benefits of certain persons and reduce those of others. In this approach wisdom is aimed at achieving the common good, while being aware of the fact that the common good will be "better" for some than for others (Sternberg et al., 2007, p. 146). The authors do not assume that the definition offered by them is the one and only definition of wisdom, but it is a definition which has proven useful in designing and implementing programs aimed for developing wisdom in students (Sternberg et al., 2007, p. 145).

One of the most popular theories is the Berlin Wisdom Paradigm, developed by Paul Baltes and his colleagues (Baltes and Smith, 2008). The Berlin Paradigm defines wisdom as an area of knowledge, called pragmatic fundamental life, that applies to: life planning (what objectives are pursued in the future and how?), management of life (How to best cope when confronted with a critical problem?) and evaluate their lives (what is the best way in which one can make sense out of personal history and experiences?) (Staudinger \& Gluck 2011). Within this paradigm five criteria of excellence in fundamental pragmatics of life are formulated. Two of these criteria are involved in all kinds of expertise: procedural knowledge (heuristics and strategies to give meaning to life and to coordinate life) and declarative knowledge (or factual- knowledge: human nature, variations in the development, coordination of state well own and others). Furthermore, three meta-criteria are formulated which are specific to wisdom. One of these is the developmental contextualism: in order to define and identify wisdom it must be taken into account several aspects such as life context, changes in socio-cultural and historical period. The second meta-criterion is relativism of values and priorities in life. It contains knowledge about tolerance and capitalizing on interindividual differences, interests and concern for the common good related to values. The third meta-criterion is the recognition and management of uncertainty, which is based on the following assumptions: information processing is limited, individuals have access to certain parts of reality and the future can not be fully understood (Baltes \& Staudinger, 2000). The terms of meeting the common good, although not explicitly expressed, often representing a critique of this paradigm is still caught in theory, one of the aspects that describe meta-criterion relativism of values and priorities in life. It is this aspect of orientation, balance between one's own interests and those of others that is clearly surprised by Sternberg in a complicated but comprehensive definition (Bassett, 2015)

The methodology used in this approach to assess wisdom involves the recording of participants in the process of thinking aloud and its evaluation against strict criteria of: cognitive functioning advanced system expert knowledge and expert knowledge in life planning and organization (Baltes, Kunzmann 2003, how in Benedikovicova \& Ardelt, 2008, p. 180). The answers 
provided by the participants are evaluated in terms of conceptualization of wisdom. The Berlin Paradigm and Sternberg's theory are explicit theories of wisdom. Therefore, to develop theories about wisdom, one must use expertise and knowledge in the field (Ardelt, 2010). The assessment method developed by the research group in Berlin is one of the first attempts to assess wisdom, which has been widely used in studies. Although it has been used extensively in research, this method has limitations. Evaluating wisdom by comparing the response participant is time consuming, which makes its use in studies with large samples difficult and impractical since it requires the transcription of verbal responses of the participants and their assessment conducted by at least two independent reviewers (Ardelt, 2010). This approach emphasizes the role of cognitive dimensions, so that wisdom can be seen as a utopian concept, representing the highest point of human development (Benedikovicova \& Ardelt, 2008, p. 180).

If the Berlin Paradigm emphasizes the role of cognitive dimensions, with wisdom being seen as a utopian concept, representing the highest point of human development (Benedikovicova \& Ardelt, 2008, p. 180), Ardelt's approach is more complex and comprehensive. Thus, wisdom is not limited to cognitive or intellectual dimensions, but includes the whole personality of the individual. Wisdom is conceptualized as a latent variable that combines cognitive, reflective and emotional features (Benedikovicova \& Ardelt, 2008, p. 180). Implicit theories of wisdom, unlike explicit ones, evaluate the common sense meaning of wisdom, meaning wisdom in different communities (Ardelt, 2003). Although most definitions of wisdom contain the cognitive and reflective component, they are often neglecting the affective component (Ardelt, 2003 , p. 277). Investigations that have focused on determining the implicit theories of individuals of different age groups, confirmed that many people identify emotional traits as an important element of wisdom, besides cognitive and reflective features (Ardelt, 2003, p. 280). Ardelt's theory, which uses the measuring instrument Three Dimensional Wisdom Scale questionnaire (3D-WS) is derived from studies previously carried out and Birren Clayton (1980), in the implicit theory of wisdom. In addition to the intellectual, cognitive dimension which is characteristic of the western approaches of wisdom, this theory captures eastern wisdom approaches (Benedikovicova \& Ardelt, 2008, p. 181). The cognitive dimension of wisdom is defined by the desire to know the truth, to understand life and the deeper meanings of the world. Cognitive dimensions are summarized in the knowledge and acceptance of the positive and negative limits of the human condition, the unpredictability and uncertainty. The reflective dimension of wisdom is defined as the ability to perceive events from multiple perspectives; it is based on a careful assessment of self and personal insight. Not ultimately, affective dimension is defined by sympathetical love and compassion to others, thus a wise person shows emotions, positive behaviors and care for others, negative or indifferent emotions and behaviors being absent (Ardelt, 2011, p. 243).

\section{The present study}

The current study seeks to identify the antecedents of wisdom, which processes develop before developing wisdom. Why is it important to identify the antecedents of wisdom? Because in this way we could intervene indirectly on the development of wisdom by creating and implementing programs that target exactly those processes. Wisdom will be studied in relation to several processes such as: general metacognition, moral metacognition, cognitive empathy, emotional empathy, irrationality and cognitive flexibility.

In the field literature, wisdom was studied in relation to intelligence; therefore a new element of the current study is investigating wisdom by putting it in relation to general metacognition. General metacognition is a part of higherlevel cognitive processes, enabling control of mental activity and learning. It is what guides us in the selection and evaluation of cognitive tasks. Metacognition could be important for wise people because they are described as being capable of making the right decisions. Such a decision requires a knowledge base, a set of strategies to be used when faced with problematic situations and knowledge to determine which strategy is better for that situation (Schraw \& Denninson 1994 ). The decisions taken by wise people are correct not only because of the end result, but also because of balancing the interests of various parties. Thus, another process that could be involved in wisdom is moral metacognition, which is the use of metacognition in solving specific moral dilemmas (McMahon \& Good, 2015). The goal, the result of wisdom is considered to be prosocial behavior oriented towards others (Ardelt, 2003), so that wisdom has been studied in connection with empathy. In the present study we differentiate between cognitive empathy, which generally refers to the ability to understand the perspective of the other, and emotional empathy, involving experiencing an emotion in response to the state of another person (e.g. feeling delight response the joy of someone) "(BaronCohen et al., 2015, p.2). Although empathy and wisdom were studied together (Marcum 2013), the novelty of this study is to examine empathy with the distinction between the two categories of empathy (emotional and cognitive empathy). Also, we use the theory of Ardelt, and an instrument based on this approach to evaluate wisdom, previous studies having investigated the relationship between empathy and wisdom using only the Berlin Paradigm.

Worldwide, mental disorders ranked third in the causes of morbidity after cardiovascular disorders and cancer (Alonso et al., 2004, cit in Gavita \& Duta, 2013). The main approaches to psychopathology are investigating the mechanisms involved in cognitive-behavioral therapy and rational emotive and cognitive behavior therapy. Both approaches underline the importance of the cognitive component, emotional regulation skills, expressed in attitudes, perceptions and thoughts that a person has of a particular situation, about themselves and others. Thus, psychopathology wellhead lies in how the person interprets situations which occur, the meanings we assign to those situations and not the situations and events by its self (Gavița, Duță, 2013). When the person assigned negative meanings, rigid, leading to the installation's distress and / or psychopathology, we say about that cognitive style that it is irrational. If instead the person interprets the situation flexible, considering that he or she can cope with it, the result being that the cognitive style is adapted to reality, we say that this cognitive style is rational. According to the literature we have identified four types of irrational thoughts that have maladaptive consequences for the person (DiGiuseppe, 1996 DiGiuseppe et al., 2012 cit in. Gavița, Duță, 2013). These types of irrational thinking are cognitive rigidity (eg "The others must be honest with me"); catastrophizing ( „It's terrible if others do not treat 
me right."); low tolerance to frustration (eg „I can not stand that others do not treat me right „) and global evaluation (eg,'If others do not treat me right, that means I'm a bad person who does not deserve anything from their side „). Previous studies have shown that wisdom is associated with better decisions, with better reasoning and actions, contributing to a happy life (Kékes 1983, 1988; Maxwell, 2004; Nozick, 1989; Nussbaum, 2001; Thiele, 2006 cit in Baltes and Smith, 2008), which indicates the presence of adaptation to reality and absence of psychopathology indices, which explains why the researchers were interested in studying wisdom and irrationality. Such study was conducted in 2010 by Kordacova and the results of the study have shown that the relationship between wisdom and irrationality is a significantly negative one: the more a person had higher scores on wisdom, while the results for irrationality were lower.

Cognitive flexibility (FC) is a property of the executive functions and is the ability to conduct appropriate adjustment in response to changes in the environment. It allows the individual's disengagement from a previous set of rules and the implementation of new rules for the efficient execution of current tasks (Diana. JN Armbruster, K. Ueltzhoffer, U. Basten, Christian J. Fiebach, 2012). FC was associated with increased resilience against negative events, a higher quality of life and increased wisdom was negatively associated with irrationality (Kordacová, 2010). Cognitive flexibility has not been studied so far in relation to wisdom, and in this study will be evaluated both through a computerized task, assessing participants' reaction times and with a self-report scale. Given the data from the literature, the study aims to investigate the relationship between wisdom and processes mentioned and described above: general metacognition, moral metacognition, emotional empathy, cognitive empathy, irrationality and cognitive flexibility. The design used will be a cross-sectional and correlational one. The assumptions made from data in the literature are:

$\mathrm{H} \mathrm{1}$ : Wisdom would positively correlate with general metacognition.

H 2: Wisdom would positively correlate with moral metacognition.

H 3: Wisdom would positively correlate with cognitive empathy.

$\mathrm{H}$ 4: Wisdom would positively correlate with affective empathy.

$\mathrm{H}$ 5: Wisdom would negatively correlate with irrationality.

H 6: Wisdom would significantly and positively correlate with cognitive flexibility.

The overall objective is to identify potential cognitive and emotional precursors of wisdom, while the exploratory objective is to identify the combination of processes that predict most of the variance of wisdom.

\section{Method}

\section{Participants}

The sample of this study is composed by mainly students, with the average age $\mathrm{m}=24, \mathrm{SD}=6.44, \min =18$, $\max =48$. The total number of participants in the assay was introduced to $\mathrm{N}=100$. In this sample the percentage of female participants was a majority ( $87 \%$ female, $13 \%$ male). However there is a difference between the number of participants used for analysis. From data obtained from the questionnaires the number of participants eligible for data analysis was 100. In the analysis of data obtained from the computerized test that assessed cognitive flexibility $\mathrm{N}$ $=57$. The difference in the total number of participants analyzed is due to the filter applied for the computerized task, so there were introduced in the final analysis only those participants who answered correctly in $70 \%$ of trial sites. A threshold effect size estimated at $\alpha=0.05$ and $\mathrm{N}=$ 100 is 0.3 .

The sample is made up of Romanian-speaking people aged over 18 years. There are no age limits or selection criteria for participation in the study. To participate in the study, participants had to agree to a consent made electronically provided when completing the first part of the study, the questionnaires. The second part of the study contained the task of assessing cognitive flexibility. Platform access was available only for those who have entered valid email addresses in the first part of the study, as access to platform was based on the e-mail. In the second part of the study we used exclusion criteria using load response rate flexibility to avoid inclusion of participants who were not careful enough performing the task. To partake in the study, participants were rewarded with 15 hours of practice, if the were psychology students and were given the summary results in an individualized report. Also, for those interested, we organized a debriefing meeting, where we shared the results of the study.

\section{Measures}

In this study we used both self-report measurements (e.g. scale assessment of metacognition moral empathy) and performance metrics (computerized assessment of cognitive flexibility).

Wisdom was measured using the Three Dimensional Wisdom Scale (3D-WS) developed by Monika Ardelt (2003). This decision is based on two reasons, one theoretical and one due to the psychometric characteristics of the instrument. Ardelt theory is very new, in comparison with other theory but after analyzing the scale built on the theoretical model of Sternberg we can see that the 6 dimensions of wisdom, can be reduced to the dimensions given by Ardelt: cognitive, emotional and reflexive (Ardelt, 2003). According to Western tradition, wisdom is seen especially through its cognitive characteristics (the ability to reason- as explicitly mentioned in the paradigm Berlin), while Eastern wisdom tradition is characterized by flexibility, honesty, selflessness and understanding. Ardelt (1997, 2000) defines wisdom as a combination of personality traits: cognitive, emotional and reflective, relying in this endeavor both implicit theories and the existing explicit Eastern tradition (Ardelt, 2003). Given the objectives of this study, 3D-WS proved to be the best option because the assessment of wisdom has qualities superior to other measurement tools of wisdom and it also considers characteristics of Eastern culture. The instrument consists of 39 items and 3 dimensions. The cognitive dimension contains 14 items, reflective dimension contains 12 items, and the affective dimension contains 13 items.

General metacognition was measured using the Assesing Metacognitive Awareness (MAI) built by Gregory Schraw (1994). It contains 52 items and can be administered to adults and adolescents. Items are classified into eight subcomponents, subsumed under the umbrella of two broad categories: knowledge of cognition and regulation of cognition. For scoring, it uses continuum scores in contrast to using a Likert scale from 1 to 5 (Schraw \& Dennison, 1994). 
There are few tools that aim to investigate moral metacognition. In this study we used the Moral Metacognition Scale (MMS) which, according to the authors, is the first domain-specific instrument. Following administration of 20 items of MMS, the results demonstrated the existence of four factors: regulation of cognition, declarative knowledge, procedural knowledge and conditional knowledge. In accordance to existing data in literature, the Moral Metacognition Scale is easy to manage (as is a Likert scale, where $1=$ strongly disagree and $6=$ strongly agree), but also has good psychometric characteristics.

Cognitive and affective empathy was measured using the Interpersonal Reactivity Index (IRI), which was developed by Davis $(1980,1996)$ and it is the most widely used measure of self-reported empathy (Alterman et al., 2003). This instrument consists of 28 items and four subscales assessing both the cognitive and the emotional component of empathy. Each subscale consists of seven items. The Perspective Taking subscale (PT) illustrates the cognitive component of the scale and evaluates the challenge to adopt the other's perspective. The Empathy Concern subscale (EC) is evaluating experiencing theone's compassion towards people who are in distress, while Personal Ditress, a second subscale, measured their emotions of anxiety and discomfort arising from the observation of negative experiences. The last subscale is Cognitive Fantasy assessing trend identification with characters from movies, games and books, etc. It is believed that IRI can be a valid measurement for the two facets of empathy.

Empathy was measured using another tool, to increase the fidelity of measurements: the Questionnaire of Cognitive and Affective Empathy (QCAE) (Reniers, Corcoran, Drake, Shryane, Völlm, 2011).

Cognitive flexibility evaluation was done in two ways: first it was assessed using a self-reported scale, then using a performance evaluation task. Thus, we used the Inventory for Cognitive Flexibility Inventory- CFI (2009), which consists of 20 items and two subscales: alternative and control.

Cognitive flexibility was measured using an adapted computer task (Armbruster, Ueltzhöffer, Basten, Fiebach, 2012). This task has been constructed according to descriptions provided by the authors to measure both flexibility and cognitive stability. Thus, the participants were shown to have four sets of stimuli, with 20 trials each. Participants are presented with a point of fixation and then one digit, which appear either at the top or the bottom of the point of fixation, or two digits. In the first type of trial one figure was shown above the point of fixation, and in that case participants had to answer whether the number is odd or even, the answer being given with the index or middle finger of the right hand (ongoing task). In the other three sets of trial sites appeared 2 digits and color intensity for each digit indicates the rules to be applied. The inhibition provided distraction; the figure that appears above the point of fixation was lighter, so participants had to continue using the rule previously applied to decide whether the number is odd or even (distracter inhibition condition). The condition of switching the figure that appears at the bottom of the point of fixation was lighter, indicating participants shift of attention to the figure down to decide, if the number is less than or greater than 5 , the answer had be given with the middle or index finger of the left hand (task switching condition). Participants were trained so that every condition to use the brightest figure for applying the rule. The last condition was composed of ambiguous trial sites, the figures were about the same color brightness, making it impossible for participants to decide who is visually brighter and darker. These conditions evaluate spontaneous switching of the participants, ie the proportion in which participants decide to apply other rules than the previous ones, although no external queues are there to suggest this action (ambiguous condition). The figures and the conditions were set in a pseudo-randomized manner. It was presented minimum of 3 and a maximum of six trial sites between the critical conditions ongoing task (task switch, distractor inhibitor or ambiguous condition) (Armbruster et al., 2011, p. 2387-2388).

Irrationality was measured with two instruments: the Rational and Irrational Beliefs Scale (RAIBS) (C. Mogo, S. Ştefan, D. David, 2013) and Attitude and Belief Scale 2 (ABS-2). In the current study the relationship between wisdom and irrationality in the Romanian population will be studied, using both a Romanian scale assessment irrationality, Rational and Irrational Beliefs Scale (RAIBS) (C. Mogo, S. Ştefan, D. David, 2013 ), and by the use of a tool used at the international level, Attitude and Belief Scale 2 (ABS-2) (DiGiuseppe, R., Leaf, Exner, T., Robin, M., 2007). We also used the Romanian version of the ABS-II (Macavei, 2003) for evaluating irrationality.

The current study design is a cross-sectional and correlational one. Questionnaires assessing wisdom, metacognition general, moral metacognition, cognitive empathy, affective empathy, and cognitive flexibility have not yet been translated and adapted for Romanian population; as such they were translated in order to use them in the present paper.

\section{Procedure}

First the participants completed an informed consent form. The whole study was conducted online. In the first part of the study a battery of tests was completed, which measured metacognition, moral general metacognition, cognitive empathy, emotional empathy, irrationality and cognitive flexibility. Subsequently, based on email addresses which participants introduced in the first part of the study, they have received an e-mail with the link to access the complete proof computerized assessment of cognitive flexibility.

\section{Results}

\section{Descriptive analyses}

In the descriptive analysis of the data from the questionnaires were included 100 participants. Wisdom scores ranged between 90.13 and $158.91(\mathrm{~m}=124,83, \mathrm{SD}$ $=9.59$ ). To assess cognitive and affective empathy we have used two assessment tools and QCAE and IRI. For cognitive empathy we used subscale scores measured with IRI $\mathrm{M}=34.64, \mathrm{SD}=5.30$, and with the subscale QCAE M $=59.11, \mathrm{SD}=7.72$. IRI subscale scores for emotional empathy were $\mathrm{m}=28.90, \mathrm{SD}=4.79$ and QCAE $\mathrm{m}=34.91$, $\mathrm{SD}=6.02$. General metacognition was $\mathrm{m}=198.29$, $\mathrm{SD}=$ 26.36 and for moral metacognition aş measured with MMS M $=87.47, S D=11.05$. Irrationality was evaluated by using the ABS-II, $\mathrm{M}=48.13, \mathrm{SD}=27.21$ and RAIBS, $\mathrm{M}=23.65, \mathrm{SD}=26.40$. The rationality subscale scores were ABS-II, $\mathrm{M}=32.79, \mathrm{SD}=18.68$, and the scores were RAIBS $\mathrm{m}=143.30, \mathrm{SD}=33.65$. In assesing cognitive flexibility we used CFI, $\mathrm{M}=98.40, \mathrm{SD}=9.90$ (Table 2).

In the computerized task for cognitive flexibility, the average number of correct answers was 250.98 , and the 
average number of errors was 39.3. The percentage of correct answers to the 300 trials was 0.83 . For the analysis of cognitive flexibility trial we used task switching (TS), where the average number of correct answers was 13.01, percentage of correct responses averaged 0.65 , and the average response time for this condition was 1178.91 . For this condition the task switching cost was calculated in terms of reaction time $(\mathrm{M}=355.89)$ and error $(\mathrm{m}=0.25)$ (Table 1). Missing data were few and random. A score was absent from data for the affective dimension of wisdom, two scores were missing for calculating the score for dimension and a score reflective wisdom was absent for calculating IRI cognitive dimension scale. For those participants who had missing data we replaced them with the average results of measurement.
Table 1. Descriptive data- behavioral measure of cognitive flexibility

\begin{tabular}{ll}
\hline Number of trials & 300 \\
\hline Mean of correct answers & 250.98 \\
Mean number of errors & 39.3 \\
\% correct answers & 0.83 \\
Mean number of correct answer in TS & 13.01 \\
Mean for correct answer in TS & 0.65 \\
Mean TR for TS & 1178.91 \\
Costs TR for TS & 355.89 \\
Error costs for TS & 0.25 \\
\hline
\end{tabular}

Table 2. Descriptive data of measurments

\begin{tabular}{|c|c|c|c|c|c|}
\hline & $\mathrm{N}$ & Minimum & Maximum & Mean & SD \\
\hline Age & 100 & 18 & 48 & 24.02 & 6.44 \\
\hline Rationality RAIBS & 100 & 60 & 215 & 145.30 & 33.65 \\
\hline Irationality RAIBS & 100 & 0 & 110 & 23.65 & 26.40 \\
\hline Rationality ABS & 100 & 0 & 79 & 32.79 & 18.68 \\
\hline Irationality ABS & 100 & 0 & 122 & 48.13 & 27.21 \\
\hline Wisdom & 100 & 90.13 & 158.91 & 124.83 & 9.59 \\
\hline $\begin{array}{l}\text { Cognitive empathy } \\
\text { IRI }\end{array}$ & 100 & 18 & 46 & 34.64 & 5.30 \\
\hline $\begin{array}{l}\text { Afective empathy } \\
\text { IRI }\end{array}$ & 100 & 16 & 41 & 28.90 & 4.79 \\
\hline $\begin{array}{l}\text { Afective empathy } \\
\text { QCAE }\end{array}$ & 100 & 17 & 46 & 34.91 & 6.02 \\
\hline $\begin{array}{l}\text { Cognitive empathy } \\
\text { QCAE }\end{array}$ & 100 & 40 & 75 & 59.11 & 7.72 \\
\hline $\begin{array}{l}\text { Moral } \\
\text { metacognition }\end{array}$ & 100 & 53 & 116 & 87.47 & 11.05 \\
\hline $\begin{array}{l}\text { General } \\
\text { metacognition }\end{array}$ & 100 & 143 & 254 & 198.29 & 26.36 \\
\hline $\begin{array}{l}\text { Cognitive } \\
\text { flexibility }\end{array}$ & 100 & 72 & 121 & 98.40 & 9.90 \\
\hline
\end{tabular}

Table 3. Correlation matrix

\begin{tabular}{|c|c|c|c|c|c|c|c|c|c|c|c|c|}
\hline Variables & 1 & 2 & 3 & 4 & 5 & 6 & 7 & 8 & 9 & 10 & 11 & 12 \\
\hline $\begin{array}{l}\text { 1. Afective } \\
\text { empathy IRI }\end{array}$ & - & & & & & & & & & & & \\
\hline $\begin{array}{l}\text { 2. Cog. } \\
\text { Empathy IRI }\end{array}$ & $.403^{*}$ & - & & & & & & & & & & \\
\hline $\begin{array}{l}\text { 3. Afective } \\
\text { empathy }\end{array}$ & $.320^{* *}$ & .182 & - & & & & & & & & & \\
\hline $\begin{array}{l}\text { QCAE } \\
\text { 4. Cog. } \\
\text { Empathy }\end{array}$ & .017 & $.366^{* *}$ & .196 & - & & & & & & & & \\
\hline $\begin{array}{l}\text { Empathy } \\
\text { QCAE }\end{array}$ & & & & & & & & & & & & \\
\hline $\begin{array}{l}\text { 5. Moral } \\
\text { metacognition }\end{array}$ & .058 & $.560^{* *}$ & -.013 & $.519^{* *}$ & - & & & & & & & \\
\hline $\begin{array}{l}\text { 6. General } \\
\text { metacognition }\end{array}$ & .081 & $.312^{* *}$ & .023 & $.602^{* *}$ & $.625^{* *}$ & - & & & & & & \\
\hline $\begin{array}{l}\text { 7. Cogntive } \\
\text { flexibility }\end{array}$ & $.322^{* *}$ & $.490^{* *}$ & .171 & $.469^{* *}$ & $.556^{* *}$ & $.419^{* *}$ & - & & & & & \\
\hline $\begin{array}{l}\text { 8. Irationality } \\
\text { RAIBS }\end{array}$ & .033 & .100 & .046 & -.133 & -.058 & .080 & .005 & - & & & & \\
\hline $\begin{array}{l}\text { 9. Rationality } \\
\text { RAIBS }\end{array}$ & -.135 & -.178 & -.034 & .070 & -.066 & $-.208^{*}$ & -.099 & $-.729^{* *}$ & - & & & \\
\hline $\begin{array}{l}\text { 10.Irationality } \\
\text { ABS }\end{array}$ & $.373^{* *}$ & $.225^{*}$ & .109 & -.017 & .011 & -.118 & .118 & .154 & -.070 & - & & \\
\hline $\begin{array}{l}\text { 11.Rationality } \\
\text { ABS }\end{array}$ & .172 & -.045 & -.052 & $.337^{* *}$ & $-.297^{* *}$ & $-.379^{* *}$ & -.164 & .120 & .026 & $.629^{* *}$ & - & \\
\hline 12.Wisdom & $.226^{*}$ & -.185 & -.068 & $-.468^{* *}$ & $-.209^{*}$ & $-.263^{* *}$ & $-.226^{*}$ & .052 & -.033 & .117 & .151 & - \\
\hline
\end{tabular}

Notes: $* p<.05 ; * * p<.01$. 
Testing the hypotheses

To test the hypotheses we conducted correlation analysis. The criterion variable was wisdom and the predictor variables were general metacognition, moral metacognition, cognitive empathy, affective empathy, cognitive flexibility and irrationality (Table 3 ). The results showed a significant positive relationship between wisdom and affective empathy as measured with IRI subscale $(\mathrm{r}=$ $.226, \mathrm{p}<0.05)$. QCAE subscale, which measures the affective empathy, showed a slightly negative but significant relationship to the wisdom $(\mathrm{r}=-0.068, \mathrm{p}=$ 0.504). Differences between the two scores may be due to the fact that IRI was translated and used in other studies on the Romanian population, while the instrument was translated QCAE only to be used in this study. Regarding the relationship between cognitive empathy and wisdom, it was significant only for QCAE subscale $(r=-.468$, $p$ $<0.01)$. With the IRI scale, it was found to be marginally significant $(r=-.185 ; p=0.66)$. The results for the relationship between wisdom and cognitive empathy are against the estimated assumptions.

Table 4. Regression model

\begin{tabular}{lll}
\hline & Wisdom & \\
& & \\
\hline Variable & Model 1 $\beta$ & Model 2 $\beta$ \\
\hline Age & -.190 & -.158 \\
Gender & -.048 & -.054 \\
Education level & -.008 & .070 \\
Affective empathy & & $.274^{* *}$ \\
Cognitive empathy & & $-.478^{* *}$ \\
General metacognition & & .097 \\
Moral metacognition & & .056 \\
Cognitive flexibility & & -.158 \\
$\mathrm{R}^{2}$ & .041 & .308 \\
$\Delta \mathbf{R}$ & & .267 \\
\hline \multicolumn{1}{c}{ Notes: $* * p<.01}$. &
\end{tabular}

In the case of general metacognition and moral metacognition measurements, the results indicated a significant but negative correlation with wisdom, contrary to the initial assumptions (MAI $r=-.263, \mathrm{p}<0.01 ; \mathrm{r}=$.209 MMS, $\mathrm{p}<0.05$ ). The hypothesis concerning a positive relationship between wisdom and cognitive flexibility has not been confirmed. Thus, cognitive flexibility showed a negative relationship with wisdom $(r=-.226, p<0.05)$. The results obtained indicated the absence of a computerized task of a linear relationship between cognitive flexibility and wisdom, so the costs in terms of response time of task switching if the condition had not shown a significant relationship with wisdom $(\mathrm{r}=.169, \mathrm{p}=.210)$. The relationship between wisdom and costs in terms of errors in the case of task switching condition has not been shown to be linear and significant $(\mathrm{p}=.093, \mathrm{p}=.491)$.

The assumption of irrationality has not been confirmed, the RAIBS Search showed a positive correlation with the intelligence, but this was not significant $(r=-.052 ; p=$ $.607)$, while the results obtained in the ABS-II indicated a non-significant positive relationship wisdom $(\mathrm{r}=.117, \mathrm{p}=$ .245). In terms of rationality RAIBS results indicated a significant negative correlation with wisdom and rationality $(r=-.033 ; p=.745)$, while the results of the ABS-II showed a positive correlation, but significant wisdom rationality $(\mathrm{r}=.151, \mathrm{p}=.134)$.
The hypothesis that asserted the relationship between cognitive flexibility and wisdom was not confirmed and the relationship between the two constructs indicated a non-linear relationship. The results obtained from the questionnaire that assessed cognitive flexibility showed a significant negative correlation $(\mathrm{r}=-.226 ; \mathrm{p}=0.024)$. As for the results of the computer task, it was given the direction of the case were not significant $(r=$ COST_RT $.169, \mathrm{p}=.210, \mathrm{r}=.093$ COST_ER, $\mathrm{p}=.491)$.

To test the objective of this study we used a hierarchical regression analysis. There have been two regression models, where the predictors explained a significant proportion of the variance in the criterion variable. In the first model we used only three factors (age, gender, educational level). In the second model including cognitive empathy, affective empathy, general metacognition and cognitive flexibility (self-reported), we included only these variables because it significantly correlates with wisdom (Table 4). Model 1 was not significant but the second model was significant (sig F Change $<.001$ ), which suggests that the variables included in model 2 explain the variance of wisdom. The total variance explained by model 2 is $25 \%$. Initially there were 4 variables which significantly correlated with wisdom in the correlation analysis. In the regression model only two variables significantly predicted wisdom: affective empathy $(\beta=.275)$ and cognitive empathy $(\beta=-.471)$. This indicates that these variables have a unique contribution explaining the variance of wisdom. For both regression models, multicolinearity it is not a risk since the mean VIF values are slightly over 1 . For model 1 VIF is 1.10 and for model 2 VIF value is 1.62 .

\section{Discussion}

The study investigated six hypotheses, one for each variable studied.

H1: Wisdom would positively correlate with metacognition.

Hypothesis 1 was not confirmed, although we expected a significant and positive relationship between wisdom and metacognition general, it turned out to be negative and significant. These results indicate a non-linear relationship between wisdom and general metacognition. For being wise, it might not be so important the amount of knowledge that an individual holds. An important role in solving problems, in addition to knowledge and strategies developed on the basis of knowledge, might be held by the experiences that people have had, the role-models to which they had access and from which they could learn effective ways to resolve difficult situations.

H 2: Wisdom would positively correlate with moral metacognition.

The second hypothesis was not confirmed. While prosocial behavior is an essential quality of those who are wise, it does not seem to be supported by moral metacognition. It is possible that apart from knowledge about what is good and what is bad, which may be important in the development of prosocial intentions, other variables are also involved in the actual prosocial behavior. Involved in making this type of behavior could be issues related to temperament, that determine the person to take the initiative, compassion, empathy or good skills in recognizing and identifying the consequences and emotions of others. 
H3: Wisdom would positively correlate with cognitive empathy.

The third hypothesis was not confirmed. Correlations between wisdom and cognitive empathy were negative and significant for both instruments that measure this construct. From these results we can conclude that to be wise does not necessary imply the increased ability to identify thoughts, intentions and motivations of others. They seem to be important and defining Sterneberg's approach, so that individuals can reach common objectives. Prosocial behavior and wisdom do not seem to be influenced or related to this skill. This ability can be useful up to a point, but if individuals would be to overuse this skill, then they would not take into account their objectives or the objectives of the society or a larger group.

H4: Wisdom would positively correlate with affective empathy.

The fourth hypothesis was confirmed: the results showed that there is a positive and significant relationship between wisdom and emotional empathy as measured by IRI. For measurements made with the instrument QCAE results were slightly negative but insignificant. Differences between the two results may be caused by instruments that were used, because each measuring instrument has errors. According to these results the ability of individuals to identify the emotions of others and resonate with the personal distress resulted from negative experiences of others is an important characteristic of wisdom. This ability could be one that allows individuals to be in direct contact with the reality and the needs of others. Reliving the emotions of others may thus be important for engaging in prosocial behaviors than cognitive empathy and simply identifying the thoughts, intentions and motivations of others. These results are consistent with those obtained in the field literature by other researchers, supporting the importance of affective empathy affective for achieving prosocial behavior, which is a defining characteristic of wisdom (Wied et al 2005; Lonigro, Laghi, Baiocco, Baumgartner , 2014).

$H$ 5: Wisdom would negatively correlate with irrationality.

The fifth hypothesis was not confirmed, so that the relationship between irrationality and wisdom has been shown to be slightly negative and significant. Instead rationality, according to results of measurements ABS, proved to have a positive relationship with wisdom. The relationship was not significant; however this could have been due to the reduced sample. It seems that in order to be wise is important to be rational even if sometimes, in different contexts, one can be irrational. What matters is the kind of thinking that prevails: even if momentarily we respond with an irrational thought, after a while when the shock of the event decreases, we are able to adapt to reality and to respond rationally to it, without having catastrophic interpretations.

H6: Wisdom would positively correlate with cognitive flexibility.

The sixth hypothesis was not confirmed, the relationship between wisdom and cognitive flexibility is in the direction predicted by the theory but it was not significant when it was measured through the computerized task. The results of the self-reported questionnaire which evaluates cognitive flexibility correlated significantly and negatively with wisdom $(r=-.226 ; \mathrm{p}=.024)$. Differences between the two methods of assessment may be due to the perception that people have about themselves when it comes to switching capabilities, and the smaller sample which was used to analyze computerized task outcomes. It is possible that those who have completed the computerized task and had a score of accuracy greater than or equal to $70 \%$ are an over-selected population. Cognitive flexibility may be an important construct în describing wise people, so that these people, when faced with difficult life situations, may consider alternative interpretations and solutions.

\section{Limits}

This study is not without limitations. Although we wanted to control the age variable, because the development of certain processes is influenced by age, the sample did not allow such analysis because the average age was 24 years with a standard deviation of 6.44. Another limitation is that were mainly used self-report instruments were mainly used, except for the computerized evaluation task of cognitive flexibility. The study had a crosssectional and correlational design; therefore, we cannot draw conclusions about the causal relationship between the variables investigated. For future directions the research could be continued by conducting longitudinal studies that aim to identify how the psychological constructs involved develop and how they interact. The advantage of these studies is that they can identify critical periods in which these constructs develop and how different constructs relate to wisdom over time. To have a more accurate representation of wisdom, future studies could use two parallel measurements to see if there are differences in accuracy and in the relationship between wisdom and the investigated constructs.

\section{Conclusions}

This paper presents the results of investigation of several constructs, which were brought together in relation to wisdom. Of all the constructs investigated only emotional empathy was found to have a positive linear relationship with wisdom. The other constructs (cognitive empathy, general metacognition, moral metacognition and self-reported cognitive flexibility) were found to have a linear correlation with wisdom, but the relationship is a negative one, contrary to the assumptions and expected results. It may be that wisdom can not be described and explained by one construct, but on the contrary wise people could be characterized by a combination of multiple constructs (regression model explained 25\% of variance wisdom).

The results obtained draw attention to the importance of studying wisdom. Many aspects are still to be explored and discovered in this area, and the information can be very useful both in the clinical field and in other areas, for example in positive psychology, improving the quality of life. The results obtained also have theoretical implications; therefore new evidence is brought to support Ardelt's approach to wisdom. Another very important thing is that although all the hypotheses have not been confirmed, the correlation between emotional empathy and wisdom has been confirmed. These results are consistent with the literature results, which claim that one of the most important factors involved in the development of pro-social behaviors is emotional empathy. The practical value of these results is that it indicates a first way in which the development of wisdom can be attempted, which has been linked to so many constructs and positive aspects of the human being. Therefore, at the practical level, it is possible to create and implement programs increasing affective 
empathy, for example in pre-adolescents or even adolescents, where the pits of wisdom can already be noticed and so after this training the changes due to this program can be identified.

\section{References}

Akin, A., Abaci, R., \& Çetin, B. (2007). The validity and reliability of the Turkish version of the metacognitive awareness inventory. Educational Sciences: Theory \& Practice, 7, 671-678.

Alterman, A. I., McDermott, P. A., Cacciola, J. S., \& Rutherford, M. J. (2003). Latent structure of the Davis Interpersonal Reactivity Index in methadone maintenance patients. Journal of Psychopathology and Behavioral Assessment, 25, 257-265.

Ardelt, M. (1997). Wisdom and life satisfaction in old age. The Journals of Gerontology Series B: Psychological Sciences and Social Sciences, 52, P15-P27.

Ardelt, M. (2003). Empirical assessment of a threedimensional wisdom scale. Research on Aging, 25, 275324.

Ardelt, M. (2011). The measurement of wisdom: a commentary on Taylor, Bates, and Webster's comparison of the SAWS and 3D-WS. Experimental Aging Research, $37,241-255$.

Armbruster J. N. D, Ueltzhoffer K., Basten U., Fiebach J. C. (2012). Prefrontal cortical mechanisms underlying individual differences in cognitive flexibility and stability. Jornal of Cognitive Neuroscience 24:12, p. 2385- 2399.

Armbruster J. N. D., Ueltzhoffer K., Fiebach J. C., (2016). The Journal of Neuroscience.

Baltes, P. B., \& Smith, J. (2008). The fascination of wisdom: Its nature, ontogeny, and function. Perspectives on Psychological Science, 3, 56-64.

Baltes, P. B., \& Staudinger, U. M, (2000). A metaheuristic (pragmatic) to orchestrate mind and virtue toward excellence. American Psychological Association, vol. 55, no. $1,122-136$.

Baron-Cohen, S., Bowen, D. C., Holt, R. J., Allison, C., Auyeung, B., Lombardo, M. V., ... Lai, M.-C. (2015). The "Reading the Mind in the Eyes" Test: Complete Absence of Typical Sex Difference in 400 Men and Women with Autism.
Bassett, C. (2015). Much madness is divinest sense: Wisdom and development. Integral Review, 11, 135-156.

Baumeister, R. F., Bratslavsky, E., Finkenauer, C., \& Vohs, K. D. (2001). Bad is stronger than good. Review of General Psychology, 5, 323.

Benedikovicová, J., \& Ardelt, M. (2008). The three dimensional wisdom scale in cross-cultural context: A comparison between American and Slovak college students. Studia Psychologica.

David D., (2006). Tratat de psihoterapii cognitive și comportamentale. Ed. Polirom, Iasi.

Davis, M. H. (1983). Measuring individual differences in empathy: evidence for a multidimensional approach. Journal of Personality and Social Psychology, 44, 113.

Kordacova, J. (2010). WISDOM AND IRRATIONALITY: PROBE INTO MUTUAL RELATIONSHIPS1. Studia Psychologica.

DiGiusepe, R., Leaf, R., Exner, T., și Robin, M. (2007). Scala de atitudini şi convingeri 2 (adaptat de Macavei, B.). În D David (coordonator), Sistem de evaluare clinică. Editura RTS, Cluj-Napoca.

Gavița, O. A., \& Duță, Teodora (2013). The employee rational and irrational beliefs scale: Preliminary validation. Transylvanian Journal of Psychology, 14, 1939.

McMahon, J. M., \& Good, D. J. (2015a). The Mora Metacognition Scale: Development and Validation. Ethics \& Behavior, 1-38.

Reniers L. E. R, Corcoran R., Drake R, Shryane M. N, Vollm A. B (2010). The QCAE: A queastioannaire of cognitive and affective empathy. Journal of Personality Assessment, 93:1, 84-95.

Schraw, G., \& Dennison, R. S. (1994). Assessing metacognitive awareness. Contemporary Educational Psychology, 19, 460-475.

Staudinger, U. M., \& Glück, J. (2011). Psychological wisdom research: Commonalities and differences in a growing field. Annual Review of Psychology, 62, 215-241.

Sternberg, R. J., Reznitskaya, A., \& Jarvin, L. (2007). Teaching for wisdom: What matters is not just what students know, but how they use it. London Review of Education, 5, 143-158. 